\title{
Dependence of Elastic Deformations of Spindle- Tool Subsystem on Influence of Cutting Force Radial Component
}

\author{
O. Yu. Kazakova ${ }^{1,}{ }^{*}$ and L. B. Gasparova ${ }^{1}$ \\ ${ }^{1}$ Samara State Technical University, Samara, RF
}

\begin{abstract}
The results of field research are presented in the article. The parameters that affect the position of the tool in the spindle of the machine are determined. The tasks concerning the identification of the angular position of the tool in the spindle are solved. The issues of the influence of the cutting force radial component on elastic angular deformations in the spindle and tool contact area are considered.
\end{abstract}

Nowadays, the machine-building industry is flourishing in Russia. The demand for complex structure parts is increasing, which leads to an increase in the accuracy characteristics of the manufactured parts. The spindle-tool subsystem plays an important role in this context.

The field research was carried out on a specially developed test bed and on a coordinate boring machine [1]. For the experiment, three control tool holders 40 with the cone angle 7:24 were used (two of which had angular errors, namely, tool holders No. 1 and No. 2) as well as three tool holders used for processing on a coordinate boring machine (two tool holders with boring cutter, one tool holder with milling cutter). The tool holder with milling cutter has been used for the machining for 5 years, the tool holders with boring cutter within one year.

The dimensions of the tool holders were measured on the Derby coordinate measuring machine produced by ETALON Company. The geometric characteristics of the conical part of the tool holder were examined with the help of Talyrond roughness integrator (Figure 1). The results of the macrogeometry survey show a kind of an out-of-roundness in the tool holder with milling cutter along its larger diameter. The deflection in the tool holder with milling cutter is fixed within 18 microns.

\footnotetext{
* Corresponding author: kazakova8080@mail.ru
} 


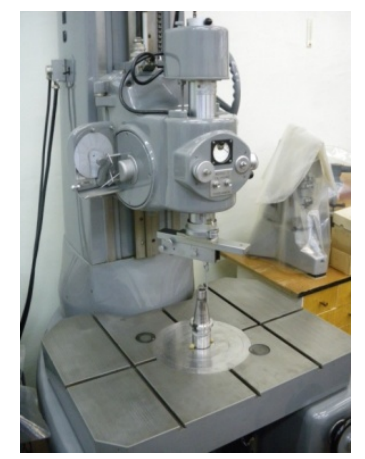

Fig. 1. Talyrond.

To identify the processes in the spindle and tool contact area, an indicator was installed on the test bed inside the contact area on the tightening of a tool holder made in the form of a mushroom knob. In addition, a loading device was installed in order to simulate the cutting force radial component (Figure 2).

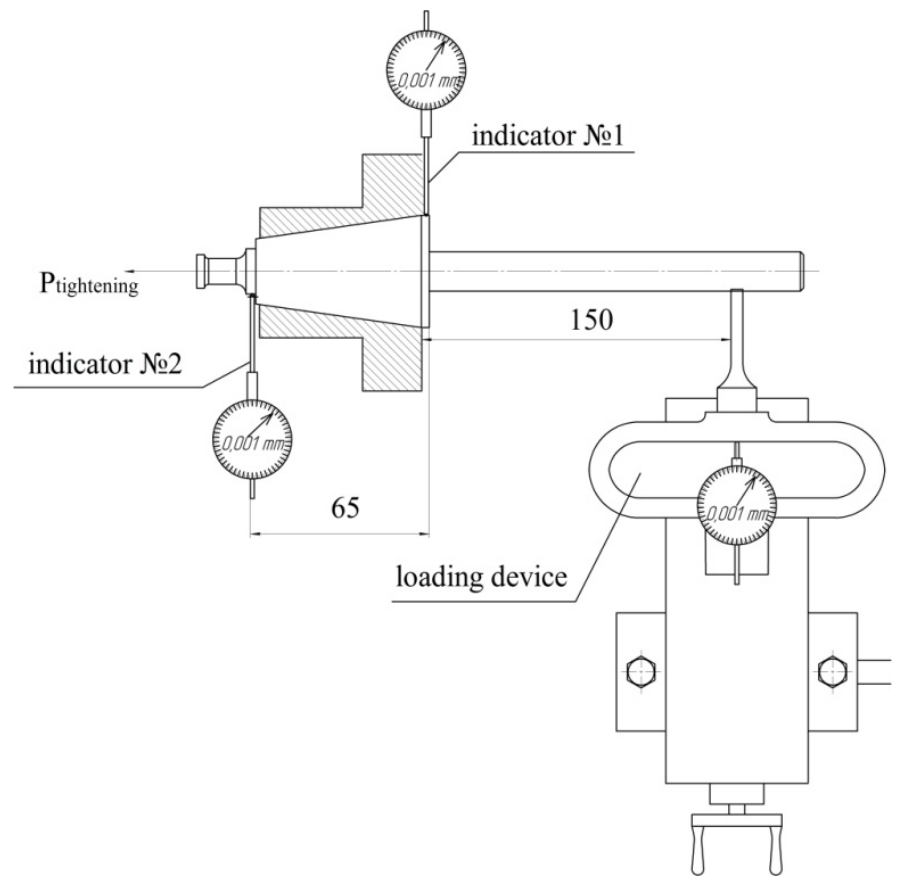

Fig. 2. Measurement design.

The value of the tool holder tightening force $P_{\text {заm }}$ made $3 \mathrm{kN}$.

The values of the cutting force radial component calculated for the terms of finishing on a coordinate boring machine by various tools are chosen within $P_{y}=500 \ldots 2,000 \mathrm{~N}$.

The value $P_{y}$ was gradually increased by the loading device up to $2,000 \mathrm{~N}$. The readings of indicators 7 and 8 were taken down. Then, with the removal of the radial load and tightening force, the tool holder was rotated every $30^{\circ}$, and the experiment was repeated 25 times. 
The results of the experiment carried out on the test bed show that the angular errors of the tool holders (control tool holders No. 1 and No. 2) increase the radial displacements, which lead to a decrease in the angular rigidity in the spindle and tool contact area by $\sim 10 \ldots$ $15 \%$ (Figure 3).

Depending on the position of the tool holders (No. 1 and No. 2) in the spindle seat, with $P_{\text {зат }}=3 \mathrm{kN}$ and the increase of the cutting force component, the angular deflection is unstable.

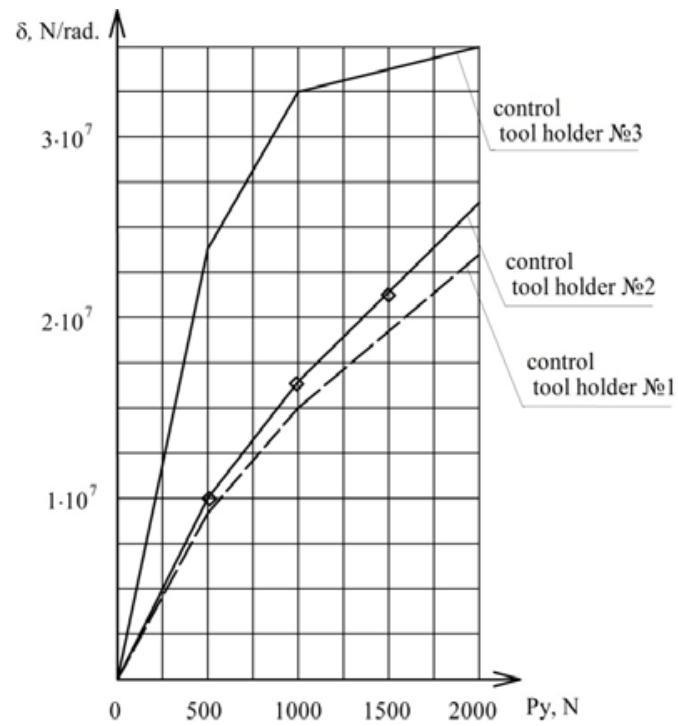

Fig. 3. Angular rigidity of control tool holders ( $\delta$ - rigidity, $\mathrm{P}_{\mathrm{y}}$ - cutting force radial component).

Also, on the test bed, during the experiment, machined tool holders were used to compare the data obtained from the control tool holders.

The research shows an increase in radial displacements in the tool holder with milling cutter by $2 \div 2.5$ times.

This fact can be associated with the presence of out-of-roundness in the larger diameter area, formed due to significant wear of the tool holder conical portion.

The results of the experiment show that the angular rigidity in the spindle and tool contact area is not constant, and increases with the increasing force. Maximum values of the angle of rotation are taken down for the tool holder with milling cutter $\left(0.03^{\circ}\right)$.

To compare the data on elastic angular deformations in the contact zone of the spindle and the tool, obtained on the test bed, the research was carried out on an operating coordinate boring machine [2].

With tightening force $P_{3 a m}=4.5 \mathrm{kN}$ in accordance with the machine certificate, the tool holder was fixed in the machine spindle. Using a dynamometer, the tool holder was loaded with the radial component of the cutting force $P_{y}=500 \ldots 2,000 \mathrm{~N}$. This force was applied to the free part of the tool holder at the distance of $L=150 \mathrm{~mm}$ from the spindle end.

In the course of experimental research of elastic angular deformations on a coordinate boring machine, it is revealed that the angle of rotation of the tool holder in the spindle seat increases with the increase in the cutting force to $2,000 \mathrm{~N}$.

The values of the angle of rotation of the tool holder with milling cutter, on average, exceed the values of the other tool holders by $2 \div 2.5$ times, which can be explained by the 
wear of the conical portion and the presence of out-of-roundness in the larger diameter area (this fact is confirmed by the research carried out on the test bed).

The angular errors of the conical part of the tool holders lead to an increase in the angles of rotation of the tool holders in the spindle, the rigidity in the spindle and tool contact area decreases by $10-15 \%$, which is also confirmed by the research carried out.

The tool holder conical portion out-of-roundness leads to an increase in the angle of the tool holder rotation by $2 \div 2.5$ times, thus reducing the system rigidity (Figure 4 ).

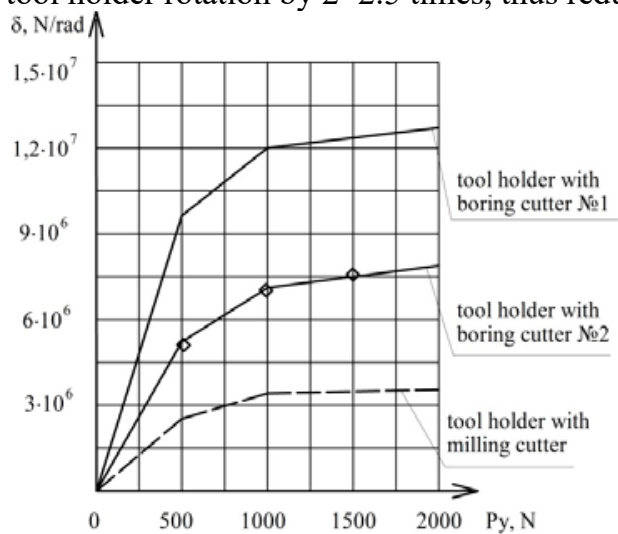

a)

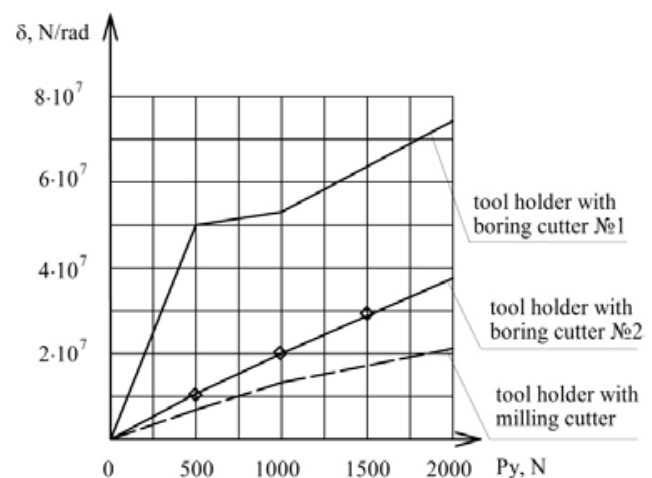

6)

Fig. 4. Angular rigidity of tool holderds: a) - test bed experiment; b) - machine experiment.

Summing up the results of the research carried out on the developed test bed, which simulates the operation of individual elements and mechanisms of the spindle assembly unit of a multi-operation machine at the time of tool change and on the coordinate boring machine, the following conclusions can be drawn:

- the angular position of the tool holder affects the accuracy of its installation in the machine spindle;

- in the course of the performed statistical processing of experimental data on the accuracy of the tool holder fixation on the machine, it can be noted that by choosing one of two possible positions for the installation of the holder in the machine spindle, it is possible to increase the accuracy of the tool system;

- a decrease in rigidity by $\sim 10 \% \div 15 \%$ in the spindle and tool contact area can be associated with the angular errors of tool holders;

- the increase in elastic displacements in the contact area by $\sim 2 \div 2.5$ times can be influenced by the out-of-roundness in the cross section of the tool holder;

- the accuracy of the positioning of the tool holder in the machine spindle increases with an increase in the tightening force, however, the recommended rational value of the tightening force makes $3 k N \leq P_{\text {зат. }} \leq 5 k N$;

- the tool holders running leads to a decrease in the tool system rigidity by $\sim 10 \% \div 15 \%$ (when the service life makes 5 years).

\section{References}

1. Kazakova, O.Yu. 2013 Improvement of Accuracy of Processing on Mill-Drill-Bore Machines by Minimizing Tool Systems Errors: Dissertation of the Candidate of Technical Science. $182 \mathrm{p}$.

2. Gasparov, E.S. Mathematical Model of Spindle Unit Bearing Assembly/E.S. Gasparov, L.B. Gasparova, Lecture Notes in Mechanical Engineering. - 2020. P. 725731. 